\title{
WIND FARM POWER OUTPUT PREDICTION BASED ON AVERAGE WIND SPEED DATA
}

\author{
Bhagyashri Koppad \\ $4^{\text {th }}$ sem MTech, Industrial Electronics \\ RNSIT, Bangalore \\ Pallavi_ap@yahoo.com \\ Ph no: 8971171150
}

\author{
Dr. Andhe Pallavi \\ Prof. \& HOD, IT Department \\ RNSIT, Bangalore \\ bhagyakoppad@gmail.com \\ Ph no: 080-28611880
}

\begin{abstract}
This paper focuses on the analysis and prediction of wind power in the Yelisirur wind farm located at Gadag district, shirahatti taluk, Karnataka. Nowadays the wind energy generation is undergoing the fastest rate of growth of any form of electricity generation in the world. The wind energy generation from the wind farms has significant influence on the stability and security of the power grid after gridconnection. One of the main difficulties of integrating large amounts of wind energy in power grids is the natural intermittency of its generated power due to the energy produced from the wind turbine being dependent on the availability of the wind, which is highly stochastic in nature. To overcome this problem, in this paper a more accurate and reliable wind power forecasting technique i.e. an integrated intelligent model is proposed based on an Adaptive Neuro-Fuzzy Inference System (ANFIS) to forecast the wind power in order to achieve a more realistic evaluation of wind power generation.
\end{abstract}

Keywords-- Wind Energy, Wind power prediction, Adaptive Neuro-Fuzzy Inference System

\section{INTRODUCTION}

Renewable sources of energy mainly including wind power offer a feasible solution to distributed power generation for isolated communities where grids are unavailable. At present scenario wind power has emerged as the most viable source of electric power is economically competitive with the non-renewable sources of energy. In such cases, isolated wind energy systems can be considered as an effective way to provide continuous power to electrical loads. One of the most promising applications of renewable energy generation lies in the development of power supply systems for remote villages that lack an economically feasible means of connecting to the main electrical grid. For the type of loads located far from a utility grid, one practical approach to selfsufficient power generation involves using a windturbine with a storage mechanism to create a standalone system [1].

A wind turbine extracts kinetic energy from the swept area of the blades. The power in the wind can be defined as follows [2]

$$
\mathrm{Pw}=\overline{\mathbf{2}} \rho \mathrm{AV} 3
$$

Where $\rho$ : Air density $(\mathrm{kg} / \mathrm{m} 3), \mathrm{A}$ : Cross sectional area of wind parcel $(\mathrm{m} 2)$, V: The wind speed $(\mathrm{m} / \mathrm{sec})$

From equation (1) it is clear that the wind power is affected by the wind speed. The wind speed at which electric power production starts is called the cut-in wind speed. The turbine will develop enough mechanical power to rotate itself at slightly lower speeds, but this wind speed will actually supply all the generator and transmission losses so that useful electric power cannot be produced. At rated wind speed the power input to the wind turbine will reach the limit for continuous operation (rated power). When the wind speed exceeds this level the excess power in the wind must be discarded by varying the pitch angle of the blades to prevent the turbine overloading. The power is maintained at its rated value until a maximum wind speed is reached i.e. the cut-out wind speed (Vcut-out) then the turbine will shut down. The actual WTG output power with the wind speed is shown in Fig 1.

\section{Power (kilowatts)}

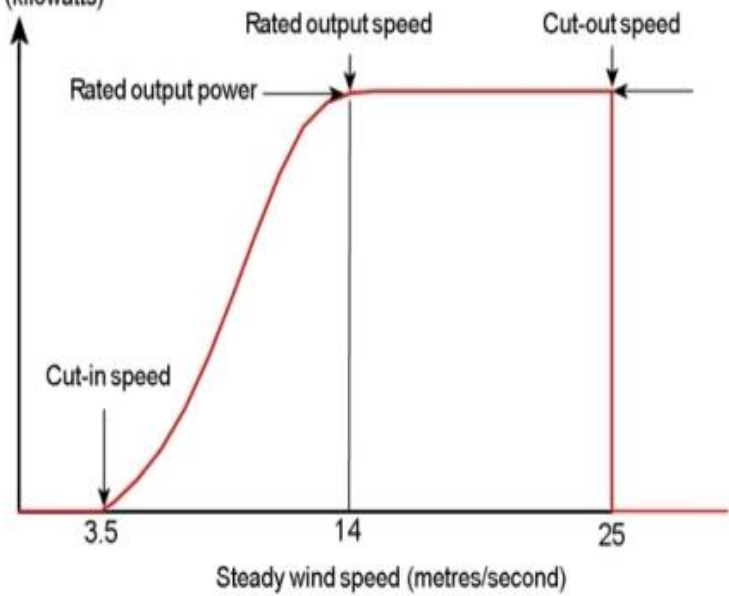

Fig. 1 Actual WTG output power with the wind speed 


\section{Asia Pacific Journals}

The available wind power in the turbine depends on the wind speed, which is a random variable. For the wind-farm operator, this causes difficulty in the system scheduling and energy dispatching, as the schedule of the wind-power availability is not known in advance. However, if the wind power can be reliably forecasted, the generating schedule can efficiently accommodate the wind generation. To overcome this problem a new technique based on Adaptive Neuro-Fuzzy Inference System (ANFIS) is used for forecasting wind power output up to several hours in advance is introduced in this paper.

The wind power prediction is important because it is useful for assisting operational control of wind farm. This imposes many challenges to system operators which consists of maintaining system frequency, power balance and quality of power, planning which includes uncertainty in wind power to unit commitment, load scheduling etc. Prediction of wind power is an important tool for ensuring the stability of power in the wind farm and it is necessary because of the intermittent, fluctuating and nonlinear nature of wind. Two main issues in the wind farm are how to make wind energy cost effective and how to integrate wind energy into the power grid. The wind power prediction is an effective method to this problem. To obtain proper and efficient wind power utilization, the wind power prediction plays an important role [4].

\section{YELISIRUR PLANT}

Bhoruka power corporation limited (BPCL) wind farm constructed a new wind site at Gadag district shirahatti taluka, near Yelisirur village, Karnataka of 25.5MW capacity in phase -1 using 17 Wind Turbines each of $1.5 \mathrm{MW}$ capacity. The table 1 shows the typical specifications of the wind turbines installed in this Wind farm.

\section{Table 1 Wind Turbine specifications}

\begin{tabular}{|l|l|}
\hline \multicolumn{2}{|l|}{ Typical specifications } \\
\hline Type & $\begin{array}{l}\text { Horizontal axis wind } \\
\text { turbine }\end{array}$ \\
\hline Capacity & $1.5 \mathrm{MW}$ \\
\hline No of blades & 3 \\
\hline Cut in speed & $3.5-4 \mathrm{~m} / \mathrm{s}$ \\
\hline Cut out speed & $25-34 \mathrm{~m} / \mathrm{s}$ \\
\hline Maximum wind speed & $40-72 \mathrm{~m} / \mathrm{s}$ \\
\hline Hub height & $80 \mathrm{~m}$ \\
\hline
\end{tabular}

\begin{tabular}{|l|l|}
\hline Rotor diameter & $77 \mathrm{~m}$ \\
\hline Blade length & $37.5 \mathrm{~m}$ \\
\hline
\end{tabular}

The Yelisirur Wind Farm has 1.5MWX17 Wind Turbines each having individual $33 \mathrm{KV} / 690 \mathrm{~V}$ substations as shown in fig 2. This YWF site is consists of 3-feeders or rows i.e. row-1, row-2 androw-3 each having $33 \mathrm{KV}$ line.

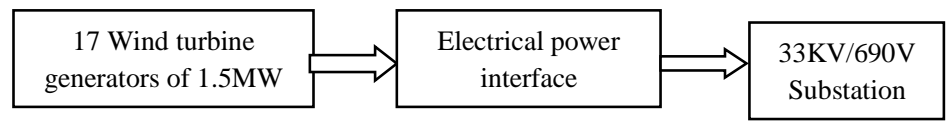

Fig. 2 Line Diagram

In the fig 2 the Electrical Power Interface block consists of Surge monitor, Isolator with earth switch, Current Transformer, Potential Transformer, HV breaker, Control and Relay panel,Transformer and LV breaker as shown in fig 3 .

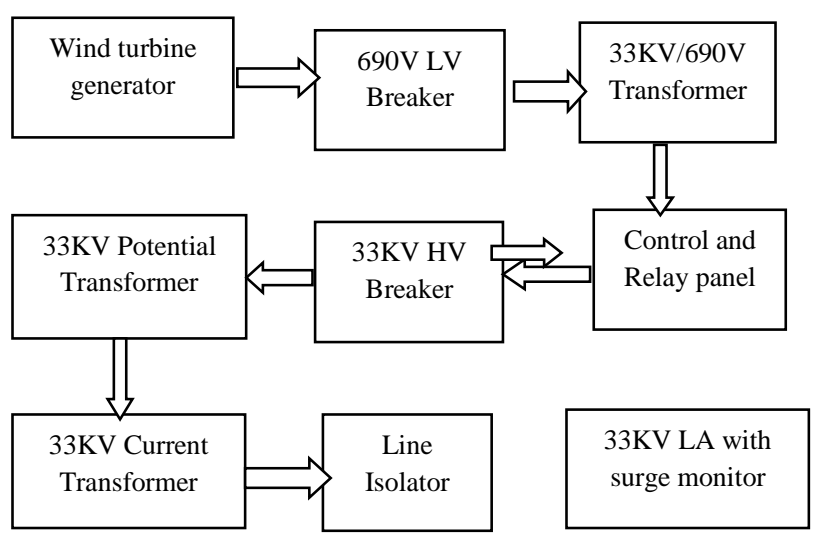

Fig 3 Electrical Power Interface

\section{ADAPTIVE NEURO-FUZZY INTERFACE SYSTEM (ANFIS)}

A hybrid of ANN and fuzzy logic, known as adaptive network- based fuzzy inference system (ANFIS), is proposed for wind power forecasting in Yelisirur Wind Farm. ANNs are simple but powerful and flexible tools for forecasting, provided that there is enough data for training. Fuzzy logic (FL) has two important advantages in data analysis. First, it reduces possible difficulties in the modeling and analysis of complex data. Second, it is appropriate for incorporating the qualitative aspects of human experience within its mapping rules, which provides a way of catching information [5]. 


\section{Asia Pacific Journals}

The entire block i.e. Electrical Power Interface shown in figure 3 can be modeled for the power output prediction using Adaptive Neuro-Fuzzy Interface System (ANFIS). A block diagram description of ANFIS model development is as shown in fig 4 .

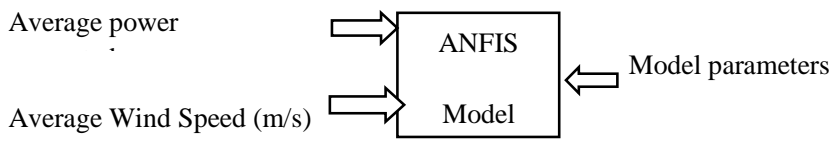

Fig.4 ANFIS Model

Training is done with one month data from Yelisirur wind farm the data consists of wind speed $(\mathrm{m} / \mathrm{s})$ and output power $(\mathrm{KW})$. The predicted output can be made more accurate with more training data. Training model is as shown in figure 5 and the predicted output is shown in table 2 .

Wind Speed $(\mathrm{m} / \mathrm{s})$

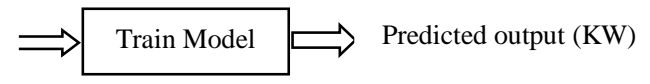

Fig. 5 Train Model

Table 2 shows the tabulation of power output obtained by Yelisirur plant, Theoretical computation and Predicted from ANFIS model.

\begin{tabular}{|l|l|l|l|l|}
\hline \multirow{2}{*}{$\begin{array}{l}\text { WTGs } \\
\text { No }\end{array}$} & \multirow{2}{*}{$\begin{array}{l}\text { Pind } \\
\text { speed } \\
(\mathrm{m} / \mathrm{s})\end{array}$} & $\begin{array}{l}\text { Yelisirur } \\
\text { plant } \\
\text { Output }\end{array}$ & $\begin{array}{l}\text { Theoretical } \\
\text { Output }\end{array}$ & $\begin{array}{l}\text { Predicted } \\
\text { Output }\end{array}$ \\
\hline 1 & 4.21 & 141.33 & 213.31 & 134.81 \\
\hline 2 & 4.36 & 179.03 & 236.94 & 181.82 \\
\hline 3 & 4.39 & 158.05 & 241.86 & 188.41 \\
\hline 4 & 4.58 & 197.83 & 274.64 & 232.09 \\
\hline 5 & 4.74 & 181.85 & 304.44 & 188.76 \\
\hline 6 & 4.81 & 229.83 & 318.13 & 216.92 \\
\hline 7 & 4.9 & 210.26 & 336.33 & 207.15 \\
\hline 8 & 4.95 & 197.12 & 346.73 & 209.88 \\
\hline 9 & 4.97 & 221.31 & 350.95 & 214.60 \\
\hline 10 & 5.14 & 228.18 & 388.21 & 218.84 \\
\hline 11 & 5.16 & 205.54 & 392.76 & 216.97 \\
\hline
\end{tabular}

\begin{tabular}{|l|l|l|l|l|}
\hline 12 & 5.31 & 223.43 & 428.01 & 217.72 \\
\hline 13 & 5.33 & 217.07 & 432.87 & 217.72 \\
\hline 14 & 5.37 & 232.05 & 442.69 & 230.24 \\
\hline 15 & 5.48 & 254.59 & 470.45 & 249.64 \\
\hline 16 & 5.5 & 264.41 & 475.62 & 261.26 \\
\hline
\end{tabular}

Figure 6 shows the Wind Turbine characteristics for Yelisirur Wind Farm, Predicted and Theoretical inputs and outputs. In the graph it is observed that the variation is present in the outputs for all the three cases. This is because of losses in the components used in the wind turbine. To overcome this problem the analysis of the prediction model is to be carried out for the recorded wind speed data to obtain the mean absolute error.

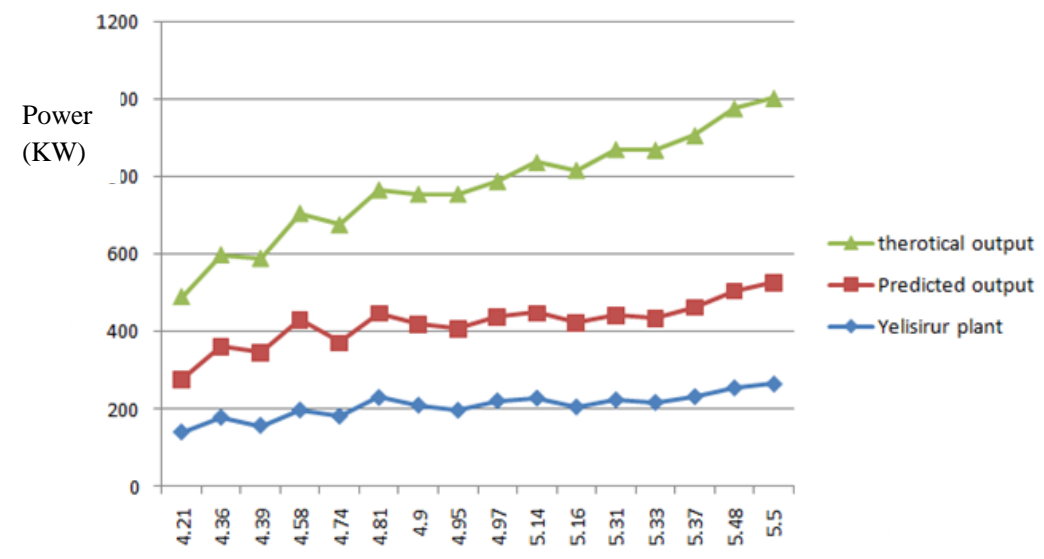

Wind speed $(\mathrm{m} / \mathrm{s})$

Fig.6 Wind Turbine Characteristics

\section{Analysis of the Prediction model}

To evaluate the accuracy of the proposed method in forecasting wind speed and wind power, different criterions are used. This accuracy is computed as a function of the actual and predicted wind speed and wind power that was generated. The mean absolute error (MAE) criterion measures how far estimates or forecasts differ from actual values. The mean absolute error for the given wind speed and wind power can be defined as follows: 


$$
M A E=\frac{1}{N} \sum_{k=11_{p m a N} N} \frac{\left|V_{\text {act }}-V_{\text {pre }}\right|}{\frac{1}{N} \sum_{N} V_{\text {act }}}
$$

Where $\mathrm{V}_{\text {pre }}$ and $\mathrm{V}_{\text {act }}$ are respectively the predicted and actual wind speed, and $\mathrm{N}$ is the number of forecasted data. In the ref [6] the analysis of the wind speed prediction is carried out to obtain the mean absolute error using the equation (2). But in this paper the analysis of wind power prediction is to be carried out for the recorded wind speed data to obtain the mean absolute error using equation (3).

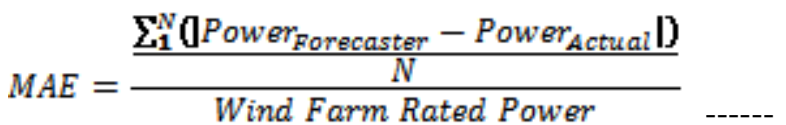
$---(3)$

Where $\mathrm{P}$ forecaster and $\mathrm{P}$ actual are respectively the predicted and actual wind power, and $\mathrm{N}$ is the number of forecasted data [7].

Using the equation (3) for the values given in table 1 the mean absolute error can be obtained as shown in table 3 .

Figure 7 shows the graph of mean absolute error for the corresponding wind turbine generators. It can be observed that the wind turbine generator 4 has the highest MAE hence it has to be serviced.

\section{CONCLUSION}

In order to increase the penetration of wind generators to the electrical grid, proper management of the dispatch of the electrical system must be acquired. In order for this to occur, it is important to have reliable and accurate techniques to forecast the wind power. In this paper an Adaptive Neuro-Fuzzy Inference System (ANFIS) technique is proposed and the analysis of wind power prediction is carried out for the recorded wind speed data to obtain the mean absolute error.
Table 3 Mean Absolute Error computation

\begin{tabular}{|c|c|c|c|}
\hline WTG s & $\mathbf{P}_{\text {actual }}$ & $\mathbf{P}_{\text {forecaster }}$ & MAE \\
\hline 1 & 141.33 & 134.81 & 0.407 \\
\hline 2 & 179.03 & 181.82 & 0.174 \\
\hline 3 & 158.05 & 188.41 & 1.896 \\
\hline 4 & 197.83 & 232.09 & 2.141 \\
\hline 5 & 181.85 & 188.76 & 0.432 \\
\hline 6 & 229.83 & 216.92 & 0.806 \\
\hline 7 & 210.26 & 207.15 & 0.194 \\
\hline 8 & 197.12 & 209.88 & 0.798 \\
\hline 9 & 221.31 & 214.60 & 0.419 \\
\hline 10 & 228.18 & 218.84 & 0.584 \\
\hline 11 & 205.54 & 216.97 & 0.714 \\
\hline 12 & 223.43 & 217.72 & 0.356 \\
\hline 13 & 217.07 & 217.72 & 0.041 \\
\hline 14 & 232.05 & 230.24 & 0.113 \\
\hline 15 & 254.59 & 249.64 & 0.309 \\
\hline 16 & 264.41 & 261.26 & 0.196 \\
\hline
\end{tabular}

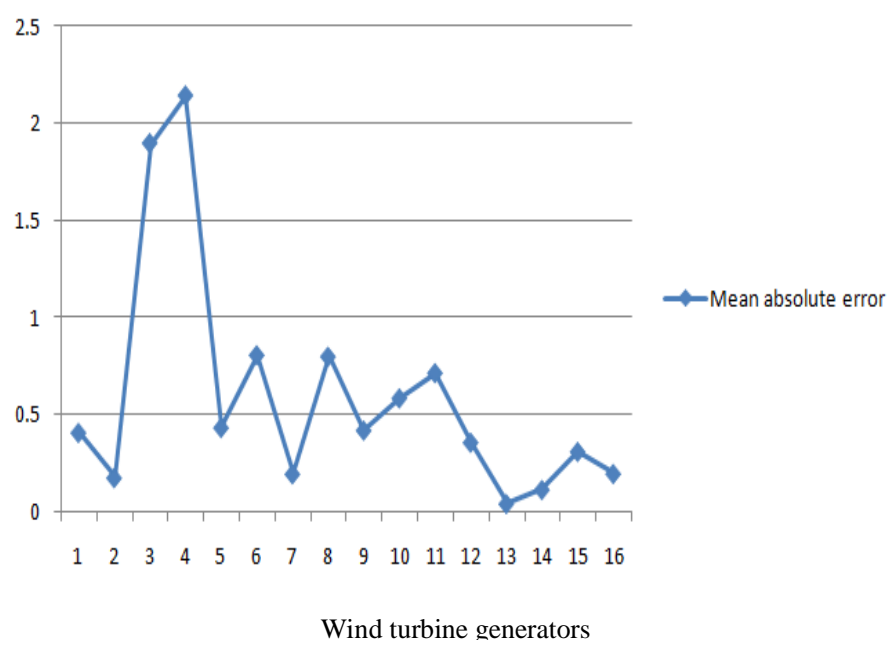

Fig.7 Mean Absolute Error

\section{REFERENCES}

[1] "Modeling and Control of a Permanent Magnet Synchronous Generator Wind Turbine with Energy Storage", K. Uday Kumar Reddy, M. Ramasekhara Reddy, Dr. 
M. Vijaya Kumar. IJERA Vol. 2, Issue 5, September- October 2012, pp.1900-1905

[2] "Stand-Alone Wind Energy Supply System Using Permanent Magnet Synchronous Generator", Udhayakumar P, Saravanan C, Lydia M. IJITEE ISSN: 2278-3075, Vol-2, Issue-3, February-2013

[3] "Average Hourly Wind Speed Forecasting with ANFIS", Fernando Castellanos, Nickel James. $11^{\text {th }}$ Americas conference on wind energy engineering June 22-26,2009

[4] "Performance analysis of modeling framework for wind speed prediction in wind farms", K. Gnana Sheela and S. N. Deepa. Scientific Research and Essays Vol. 7(48), pp. 4138 -4145, 10 December, 2012

[5] "Prediction of Wind Speed and Power in the Central Anatolian Region of Turkey by Adaptive Neuro-Fuzzy Inference Systems (ANFIS)", Ertugrul CAM, Osman YILDIZ. Turkish J. Eng. Env. Sci.30 (2006) 35-41

[6] "Wind Speed Prediction in Binalood Wind Farm Using Two Artificial Intelligent Methods", A. Abedi, M. Hasheminejad, H.Fekri, H.Razzaghi. Renewable Energy Department, Materials \& Energy Research Centre, Karaj, Tehran, Iran 2011

[7] "Wind farm power forecast in mid-eastern coastline of china", Zhengquan $\mathrm{Li}$, Zhongen Yang, Yiping Yao, Shengjun Chen, Xiaowei Zhang \& Tao Feng. IJRRAS Vol-14,issue2,February 2013 